Article

\title{
Temperature Measurements on a Solar and Low Enthalpy Geothermal Open-Air Asphalt Surface Platform in a Cold Climate Region
}

\author{
Caner Çuhac, Anne Mäkiranta * ${ }^{\mathbb{C}}$, Petri Välisuo, Erkki Hiltunen and Mohammed Elmusrati \\ School of Technology and Innovations, University of Vaasa, P.O. Box 700, FI-65101 Vaasa, Finland; \\ canercuhac@gmail.com (C.Ç.); petri.valisuo@uva.fi (P.V.); erkki.hiltunen@uva.fi (E.H.); \\ mohammed.elmusrati@uva.fi (M.E.) \\ * Correspondence: anne.makiranta@univaasa.fi; Tel.:+358-29-449-8302
}

Received: 10 December 2019; Accepted: 18 February 2020; Published: 21 February 2020

check for updates

\begin{abstract}
Solar heat, already captured by vast asphalt fields in urban areas, is potentially a huge energy resource. The vertical soil temperature profile, i.e., low enthalpy geothermal energy, reveals how efficiently the irradiation is absorbed or radiated back to the atmosphere. Measured solar irradiation, heat flux on the asphalt surface and temperature distribution over a range of depths describe the thermal energy from an asphalt surface down to $10 \mathrm{~m}$ depth. In this study, those variables were studied by long-term measurements in an open-air platform in Finland. To compensate the nighttime heat loss, the accumulated heat on the surface should be harvested during the sunny daytime periods. A cumulative heat flux over one year from asphalt to the ground was $70 \%$ of the cumulative solar irradiance measured during the same period. However, due to the nighttime heat losses, the net heat flux during 5 day period was only $18 \%$ of the irradiance in spring, and was negative during autumn, when the soil was cooling. These preliminary results indicate that certain adaptive heat transfer and storage mechanisms are needed to minimize the loss and turn the asphalt layer into an efficient solar heat collector connected with a seasonal storage system.
\end{abstract}

Keywords: asphalt solar collector; heat flux; distributed temperature sensing; low enthalpy geothermal energy; renewable energy; soil temperature profile

\section{Introduction}

Today's society is obliged to search for new low carbon energy resources to fight against global climate change. In cold-climate regions, fossil fuels are often used for heating. Solar energy, which is one of the most important inexhaustible sustainable energy resources, can be harvested using heat collectors or solar panels. Solar heat is renewable, and therefore, can potentially reduce dependency on fossil fuels. On the other hand, collecting of solar energy from the asphalt layer during the hottest season also saves the asphalt from large temperature changes, which can cause structural damage like rutting or hardening [1,2].

Surface temperature changes caused by solar irradiation degrade exponentially with a time constant of a few hours due to the thermal energy flowing back into the atmosphere. The accumulation of the daily gains or losses in terms of solar energy leads to small temperature increases in the deeper layers of the soil, creating long-term warming or cooling of the soil [3,4]. A diurnal and/or seasonal storage is necessary for a solar heating system in a cold climate region. Majorowicz et al. [5] and Loomans et al. [6] have expressed an application of an asphalt collector for summer and winter conditions. They have also studied the thermal energy potential of an asphalt collector and what the critical parameters are. 
Some simple storage systems operate without heat pumps; only solar collectors and panels are connected with seasonal thermal energy storage [7]. Solar heat collectors, together with heat pumps and seasonal thermal energy storage systems, are frequently used in heating real estate, industrial buildings, and greenhouses [8,9]. Drake Landing Solar Community in Canada has experience in the harvesting and storing of solar energy [10,11]. In Drake Landing, 52 detached houses are heated using $2293 \mathrm{~m}^{2}$ of flat plate solar collectors. The storage volume used for seasonal storage consisted of 144 boreholes, each being the depth of $35 \mathrm{~m}$. The temperature of the borehole thermal energy storage system (BTES) reached above $65^{\circ} \mathrm{C}$ in summer after three years of operation, and the temperature dropped nearly at $40{ }^{\circ} \mathrm{C}$ during the winter $[10,12]$. Experimental measurements and a Comsol simulation model of thermal energy from solar collectors in the ground were studied also by Haq and Hiltunen [13]. The theories and models used by Haq and Hiltunen can later be used to optimize the parameters of the asphalt heat collection and seasonal storage system.

The focus and novelty of this research was to study the thermal energy absorption of asphalt surface and soil layers beneath an asphalt layer in a cold climate region. The goal was reached by benchmarking and analyzing the solar irradiance and the absorption rates of the asphalt surface around the clock in different seasons. The vertical temperature distribution in the soil was studied for possible solar and low enthalpy geothermal energy harvesting applications in future.

The laboratory experiments, carried out before this study, indicated that dark asphalt is efficient in absorbing solar irradiance and conducting thermal energy to the soil [14]. Ho et al. [15] has modeled an asphalt paved area with most important parameters and variables by Comsol finite element simulation. In Finland, logistic centers are interested in snow melting systems. In this research, the thermal behavior of commonly used asphalt paved soil structures, e.g., parking spaces, is studied in high latitudes above $63^{\circ} \mathrm{N}$ at University of Vaasa campus site (see Figure 1), which is farther north than the previous research projects cited above. The monthly mean air temperatures and heating degree days in Vaasa during the study period are declared in Table 1.

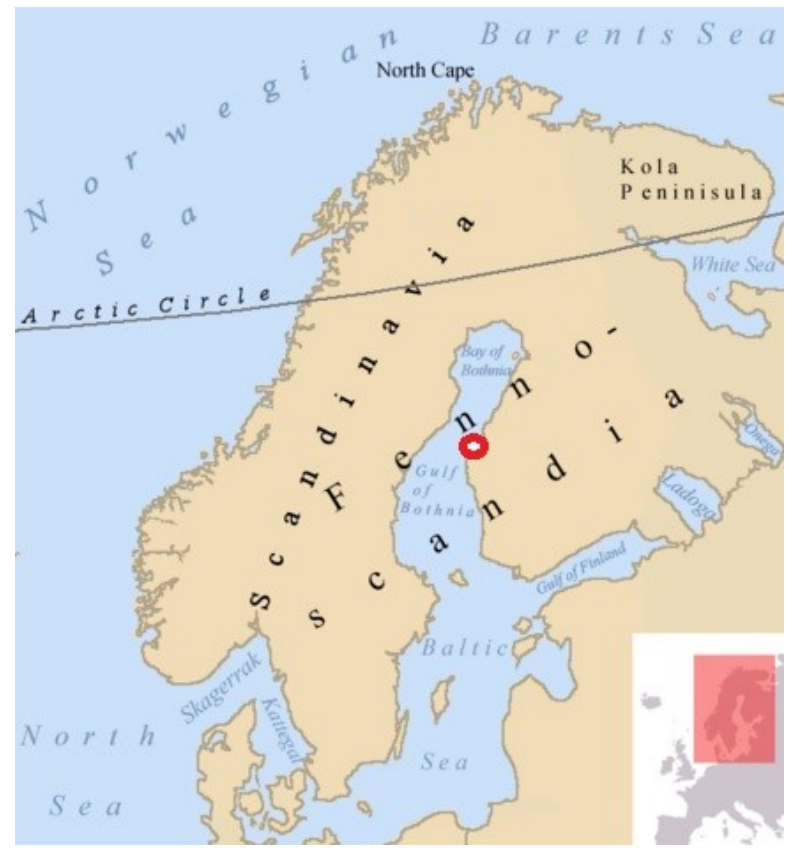

Figure 1. Location of measurement site marked by red circle, Vaasa, Finland [16]. 
Table 1. The monthly mean air temperatures $\left[{ }^{\circ} \mathrm{C}\right]$ measured during April 2014-December 2015 at the weather station of the Finnish Meteorological Institute [17] and the heating degree days (HDD) in Vaasa [18].

\begin{tabular}{cccccccccccccc}
\hline & Jan. & Feb. & Mar. & Apr. & May & Jun. & Jul. & Aug. & Sep. & Oct. & Nov. & Dec. & HDD \\
\hline 2014 & & & & 4.2 & 9.3 & 12.6 & 20 & 16.5 & 11.5 & 5 & 1 & -0.7 & 3926 \\
2015 & -3.1 & -0.2 & 0.1 & 4 & 8.4 & 12.1 & 15.2 & 16.5 & 12.1 & 5.9 & 3.9 & 1.2 & 3546 \\
2016 & -9.7 & -2.3 & 0.1 & 3.3 & 11 & 14 & 17.2 & 14.6 & 11.9 & 4 & -1.1 & -0.5 & 4124 \\
\hline
\end{tabular}

The modeling of the thermophysical properties of pavement materials on the evolution of temperature depth profiles in different climatic regions has been refereed by Hall et al. [19].

\section{Materials and Methods}

According to Strzelczyk et al. [20] it is important to know the thermal parameters of the surroundings, the weather, and the solar radiation properties in a given location in order to design and improve energy systems. The shallow geothermal energy originates mainly from sun. The measurements in this study were obtained by three main sources: (1) a pyranometer, (2) a heat flux plate, and (3) a distributed temperature sensing (DTS) system. These three independent methods complement each other, giving on a reliable picture of the different layers. The pyranometer measured solar irradiance, the heat flux plate measured the heat flux through the asphalt layer, and the DTS described the temperature distribution down to several meters' depth.

\subsection{Pyranometer Measurements}

In this research solar irradiance is measured by using a Hukseflux LP02-TR (Hukseflux Inc., Delft, The Netherlands) pyranometer [21] which was placed on the roof of the neighbour building. In this position it was under the open sky without shadows. The measured values were sampled using a DataTaker-data logger (Thermo Fisher Scientific Australia Pty Ltd.,Melbourne, Australia) in $10 \mathrm{~s}$ time intervals. The data was logged with a timestamp and stored for analysis. The calibration accuracy of the pyranometer is less than $1.8 \%$.

\subsection{Heat Flux Measurements on the Asphalt Surface}

The heat flux plate together with pyranometer can be used to study the efficiency of an asphalt layer as a heat collector. Heat flux data were collected using a Hukseflux heat flux plate HFP01-15 (Hukseflux Inc, The Netherlands) [22] buried $5 \mathrm{~cm}$ below the asphalt surface at the data collection site (see Figures 2 and 3). This sensor plate generates a small analog output voltage proportional to the net heat flux passing through it. The heat flux towards the ground is interpreted as positive and the heat flux from the ground to the surface is interpreted as negative. The aim of taking the heat flux measurements is to quantify the net energy from solar radiation absorbed by the asphalt during the day and the amount of thermal energy released back to the atmosphere during the night. These energy flows depend on multiple factors, such as irradiance, air temperature, the weather, current soil temperature, the thermal properties of the medium, thermal conductivity, and heat capacity [23]. The accuracy of calibration is $\pm 3 \%$.

A data collection system was developed for reading, transferring, and storing the ground heat flux plate data. This system consisted of an analog-to-digital converter (ADC) and a wireless sensor platform, a wireless gateway, and an embedded PC (see Figure 4). The analog voltage provided by the sensor was digitized by an ADC and the wireless sensor platform sampled the value every $10 \mathrm{~s}$ and sent the values to the wireless gateway platform located inside the building. The wireless gateway was connected to the embedded PC, which stored the data on the hard drive. During the data collection period, the measurement devices faced cold temperatures, as low as $-30^{\circ} \mathrm{C}$, and continued to operate. 


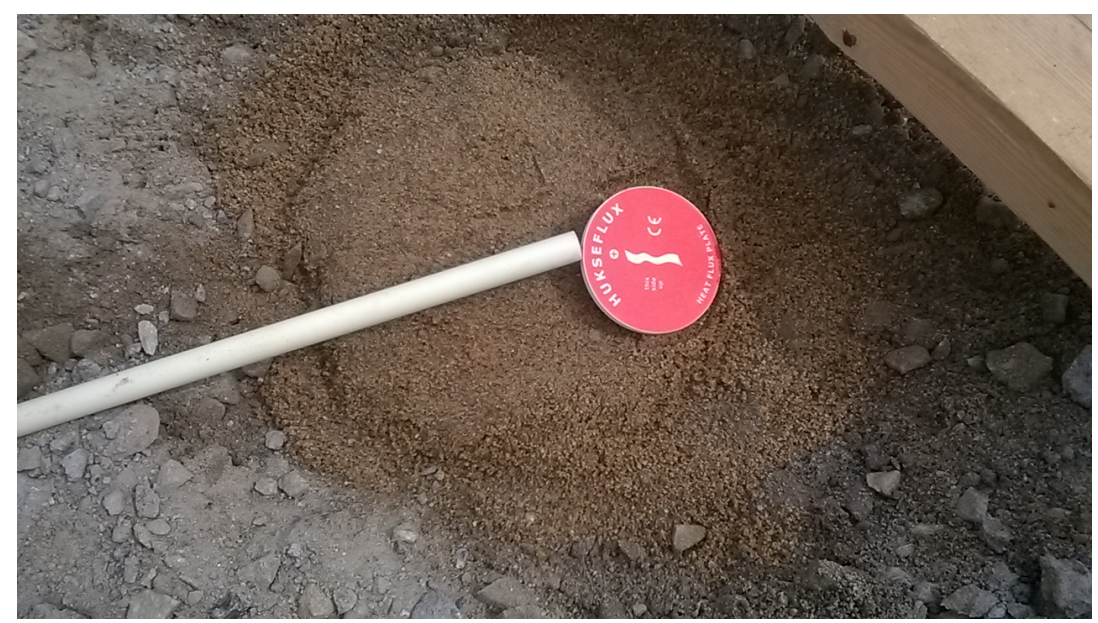

Figure 2. Installation of heat flux plate "Hukseflux" before asphalt pavement.

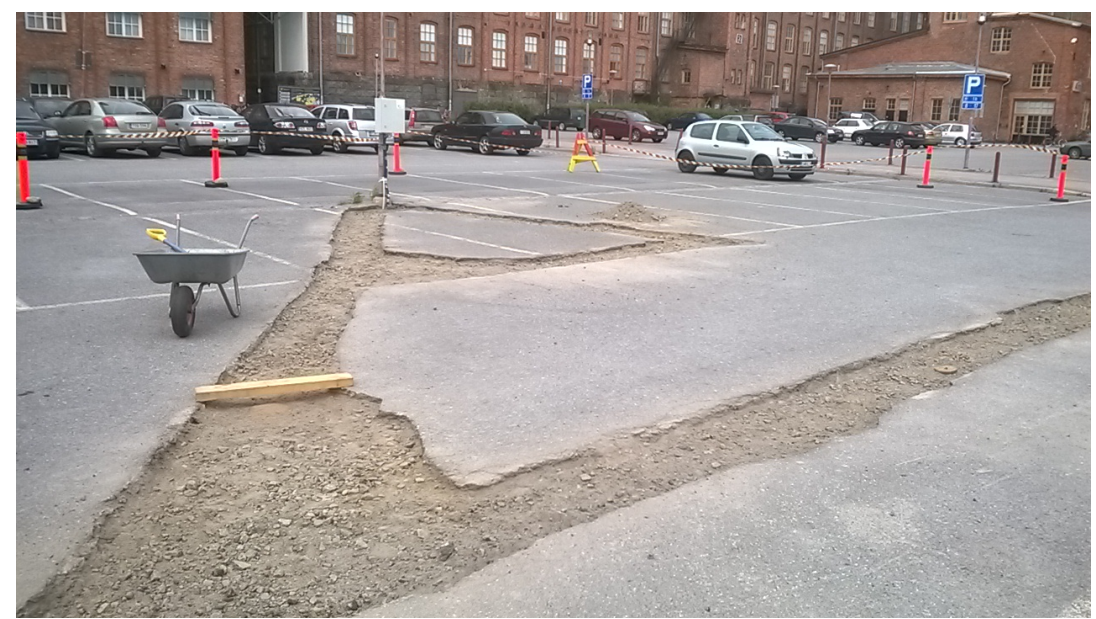

Figure 3. Heat flux data collection site, "Hukseflux," under the plank.

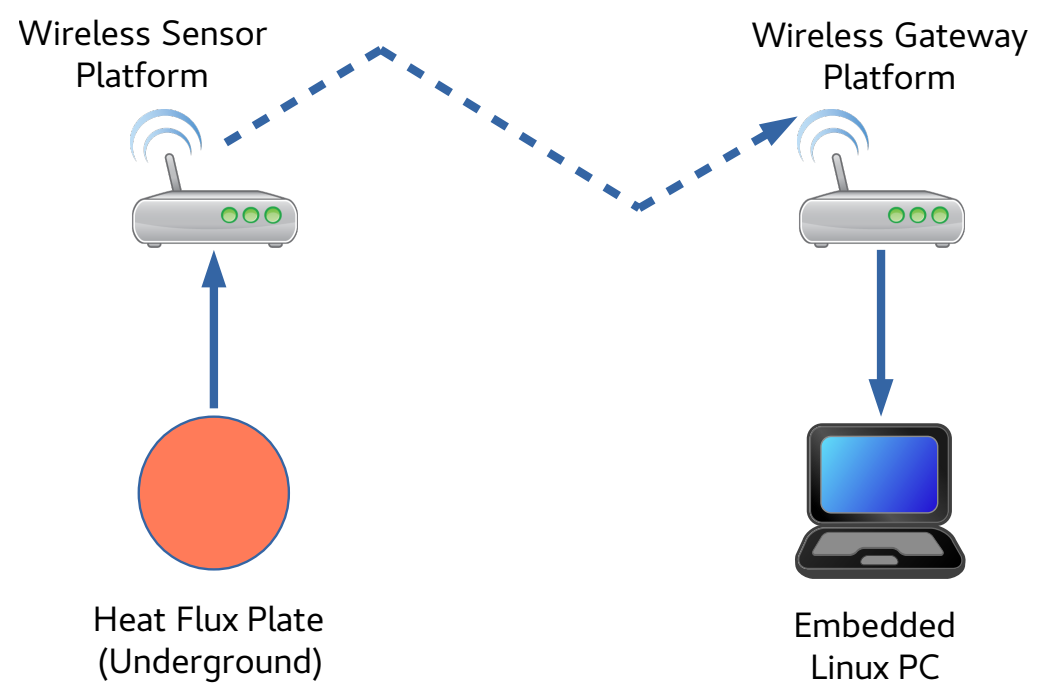

Figure 4. Network structure for wireless data collection of the heat flux sensor. 
The collected data were analyzed using the mathematical computing software MATLAB (Version 9.2., The MathWorks Inc., Natick, Massachusetts, USA) to extract information about the net flux of the heat depending on the meteorological conditions of the season and the time of day. Statistical computations were used to make the estimations of the future heat transfers.

\subsection{Underground Temperature Measurements}

The distributed temperature sensing (DTS) method was used to measure the temperatures in soil layers under the asphalt pavement. This method was chosen because it is known to be usable in cold climate regions [24] and is successfully used in monitoring of boreholes too. The boreholes can be open-holes or sealed wells, as in this study, and the installation can be permanent [25-27]. This method is based on optical light scattering in fiber [28]. Short pulses of laser light are sent to the optical fiber by the DTS measurement device. Part of the incident light pulse is scattered by elastic scattering while it moves along the core of the fiber. The properties of the scattered light are acquired by the DTS measurement device, which then estimates the temperature based on the temperature dependent part of elastic scattering $[29,30]$. An optical fiber, therefore, can be used as a linear sensor. In this study, the temperatures were observed with $1 \mathrm{~m}$ spatial resolution.

A measurement fiber was installed into the vertical boreholes drilled under the asphalt (more exactly described by Mäkiranta et al. [4]). The aim was to measure soil temperatures from the depth of $50 \mathrm{~cm}$ down to $10 \mathrm{~m}$ at the same time. Temperatures under the asphalt layer were acquired by a DTS device (Oryx DTS, Sensornet Ltd, Hertfordshire, UK) once or twice per month, depending on the season. These measurements were made on site using special instruments in addition to the meteorological data. The accuracy of the DTS device is $+/-0.5^{\circ} \mathrm{C}$.

The structure of an asphalt-paved parking lot is shown in Figure 5. The thickness of the asphalt layer is between 7 and $10 \mathrm{~cm}$, the gravel and sand layer is about $60 \mathrm{~cm}$ thick, and the clay layer lies beneath those. The physical properties of soil is listed in Table 2.

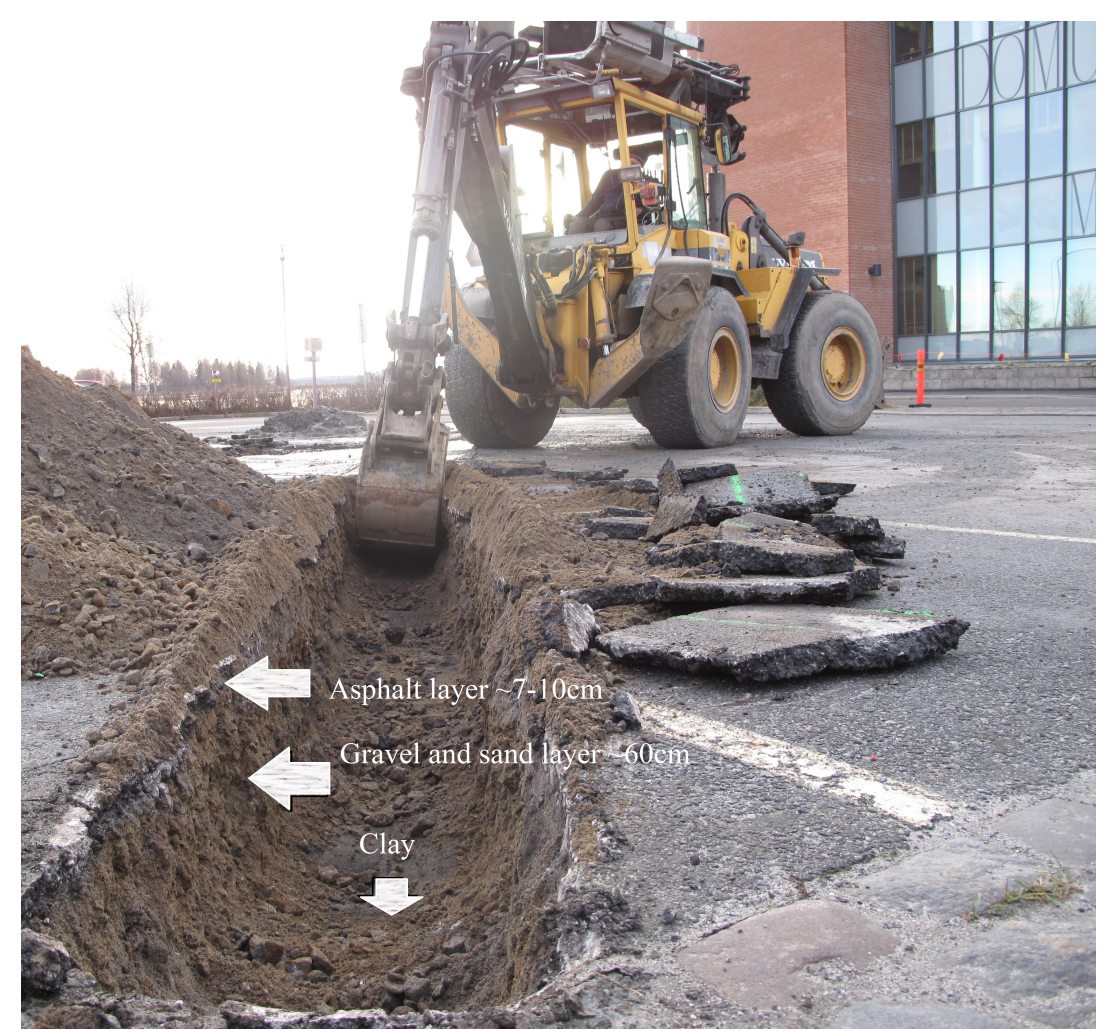

Figure 5. Soil layers under the asphalt in the measurement field at the University of Vaasa campus area. 
Table 2. Some physical properties of the soil in the literature [31-35].

\begin{tabular}{lcc}
\hline Soil Type & Specific Heat Capacity $\left[\mathbf{k J} / \mathbf{k g} \cdot{ }^{\circ} \mathrm{C}\right]$ & Density $\left[\mathbf{k g} / \mathbf{m}^{3}\right]$ \\
\hline Asphalt & 0.92 & 2400 \\
Gravel & $1.50(\mathrm{dry})$ & $1680(\mathrm{dry})$ \\
Sand & $0.84\left(\mathrm{dry}, 20^{\circ} \mathrm{C}\right)$ & 2660 \\
Clay & $0.88(10 \%$ moisture $) 1.76(50 \%$ moisture $)$ & 1600 (dry) 1760 (wet) \\
\hline
\end{tabular}

\section{Results}

\subsection{Analyzing Pyranometer and Heat Flux Data}

The ratio of the incoming solar irradiance leading to a heat flux under the asphalt can be used as a measure of the efficiency of the asphalt layer as a heat collector. The daily average absorption ratio, $\sigma$, for the given day was calculated by integrating the solar irradiance, $E_{e}$ (radiant exposure $[\mathrm{H}]=\mathrm{Wh} / \mathrm{m}^{2}$ ) and heat flux, $\phi$, over a $24 \mathrm{~h}$ period, as follows:

$$
\sigma=\frac{(1 / T) \int_{t \in T} \phi(t) \mathrm{dt}}{(1 / T) \int_{t \in T} E_{e}(t) \mathrm{dt}}=\frac{\bar{\phi}}{\overline{E_{e}}}
$$

This formula applied for the 23th of April gives the following result:

$$
\sigma=\frac{14 \mathrm{Wh} / \mathrm{m}^{2}}{230 \mathrm{Wh} / \mathrm{m}^{2}}=5.9 \%,
$$

As expected, the soil warms up in April, which is spring time in the northern hemisphere. The net heat flux is rather small due to high negative flux during the night. Liquid circulation assisted by pumps could be utilized for optimizing the heat transfer to the soil. Heat loss can also be reduced by many other technical means, such as by selecting optimal materials in different soil layers, or by using an insulating cover during the night. The full potential of the asphalt layer can be estimated by calculating the absorption ratio in an optimal case where the nighttime heat loss is totally eliminated by accumulating only the positive heat flux. The absorption ratio of this optimal case, $\sigma_{p}$, is:

$$
\sigma_{p}=\frac{139 \mathrm{Wh} / \mathrm{m}^{2}}{230 \mathrm{Wh} / \mathrm{m}^{2}}=60 \%,
$$

Although the average heat flux was $139 \mathrm{Wh} / \mathrm{m}^{2}$ during the daytime, which is $60 \%$ of the daytime solar irradiance, the absorption rate for the entire day was only $14 \mathrm{Wh} / \mathrm{m}^{2}$, which is only $5.9 \%$ of the solar irradiance. This reduction was caused by the heat loss that occurred during the nighttime; see Figure 6.

\subsection{Relation between the Cumulative Heat Flux and Soil Temperature}

The soil temperature, $T$, is directly proportional to the heat, $Q$, stored in the soil since $Q=c m \Delta T$, where $\mathrm{m}$ is the mass of the volume unit of soil $[\mathrm{m}]=\mathrm{kg} / \mathrm{m}^{3}$ and $[\mathrm{c}]=\left[\mathrm{kJ} / \mathrm{kg} \cdot{ }^{\circ} \mathrm{C}\right]$ is the specific heat capacity of soil. Since the heat, $Q$, is an integral of heat flux, $\phi$, in time $t$ and the surface $S$, the following equation, showing the dependency between soil temperature and heat flux, is obtainable:

$$
\int_{0}^{t} \oint_{S} \vec{\phi} \cdot d \vec{s} d t=c m \Delta T
$$

where $\phi$ is the heat flux into the unit of soil volume surrounded by the closed surface, $S$, during time $d t$.

The pyranometer and the heat flux plate data were used for estimating the absorption efficiency of the asphalt layer. Changes in the underground temperatures were acquired using the DTS measurement method, and they are proportional to the integral sum of the net heat flux. 
As an example of daily data analysis, Figure 6 represents the measured solar irradiance and heat flux on the 23rd of April.

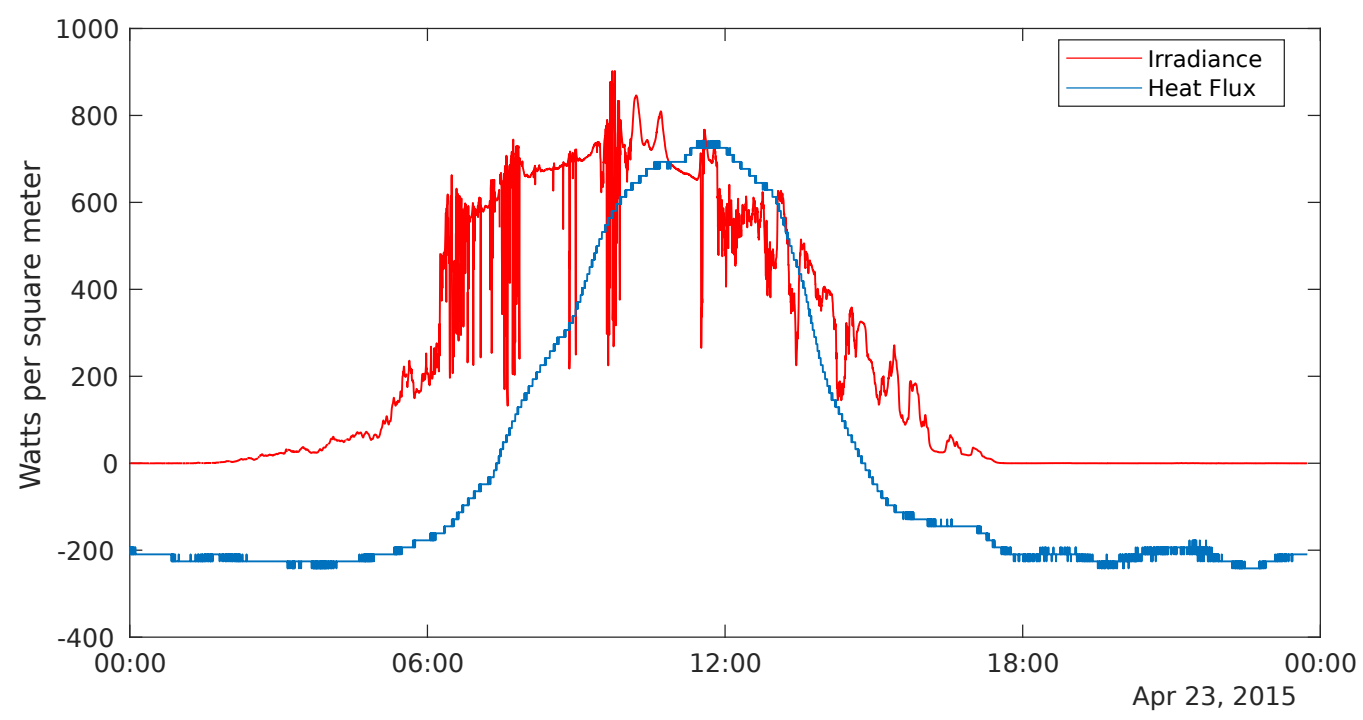

Figure 6. Solar irradiance, $E_{\mathcal{e}}(t)\left[\mathrm{W} / \mathrm{m}^{2}\right]$ (pyranometer) and heat flux, $\bar{\phi}\left[\mathrm{W} / \mathrm{m}^{2}\right]$ (heat flux plate), as a function of time $(h)$ for the 23rd of April 2015.

The solar irradiance measured by the pyranometer is always positive since it represents the solar energy received as watts per square meter. The data shown in Figure 6 spans from 00:00 until 23:59. The sunlight on the 23rd of April 2015 started at 3:30 due to the northern latitude of Finland and lasted until 17:00, having a peak of $900 \mathrm{~W} / \mathrm{m}^{2}$ at 11:00. The data were sampled every $10 \mathrm{~s}$ and included relatively large and fast fluctuations due to cloud shadows and reflections.

Figure 6 also represents the net heat flux, $\phi$, through the asphalt surface for the same day. Heat flux can have negative values when the thermal energy is dissipated back onto the surface from the ground. The figure shows that the solar irradiance induces a positive heat flux towards the ground, whereas the heat flux becomes negative when the irradiance is close to zero. The solar irradiance must be greater than the heat loss to achieve positive heat flux. The heat loss depends on the soil temperature, air temperature, and the weather conditions. The heat loss is relatively small in spring when the soil is still cool and relatively high in autumn when the soil is warm. Although the peak heat flux was $700 \mathrm{~W} / \mathrm{m}^{2}$, the average heat flux $\bar{\phi}$ for the given day was only $14 \mathrm{~W} / \mathrm{m}^{2}$. The average heat loss was approximately $130 \mathrm{Wh} / \mathrm{m}^{2}$.

Figures 7-10 illustrate the instantaneous balances during 5 day periods of heat flux (average net heat flow and average positive heat flow are measured with heat flux plate, including diffuse irradiance) and irradiance (direct solar irradiance measured by pyranometer) in four different seasons. The data shown in the figures are summarized in Table 3. Heat flux value for autumn is negative because the soil is still warm but is cooling down continuously. In winter, the positive heat flux is small, depending more on the air temperature than negligible irradiance, and losses are small due to the annual soil temperature minimum and the insulating snow cover. The soil starts warming quickly during spring when the irradiance is increasing but the soil temperature is still low, keeping losses small. Solar irradiance is greatest during the summer, but the net heat flux is not very strong because the soil is already warm and the losses are also high. 


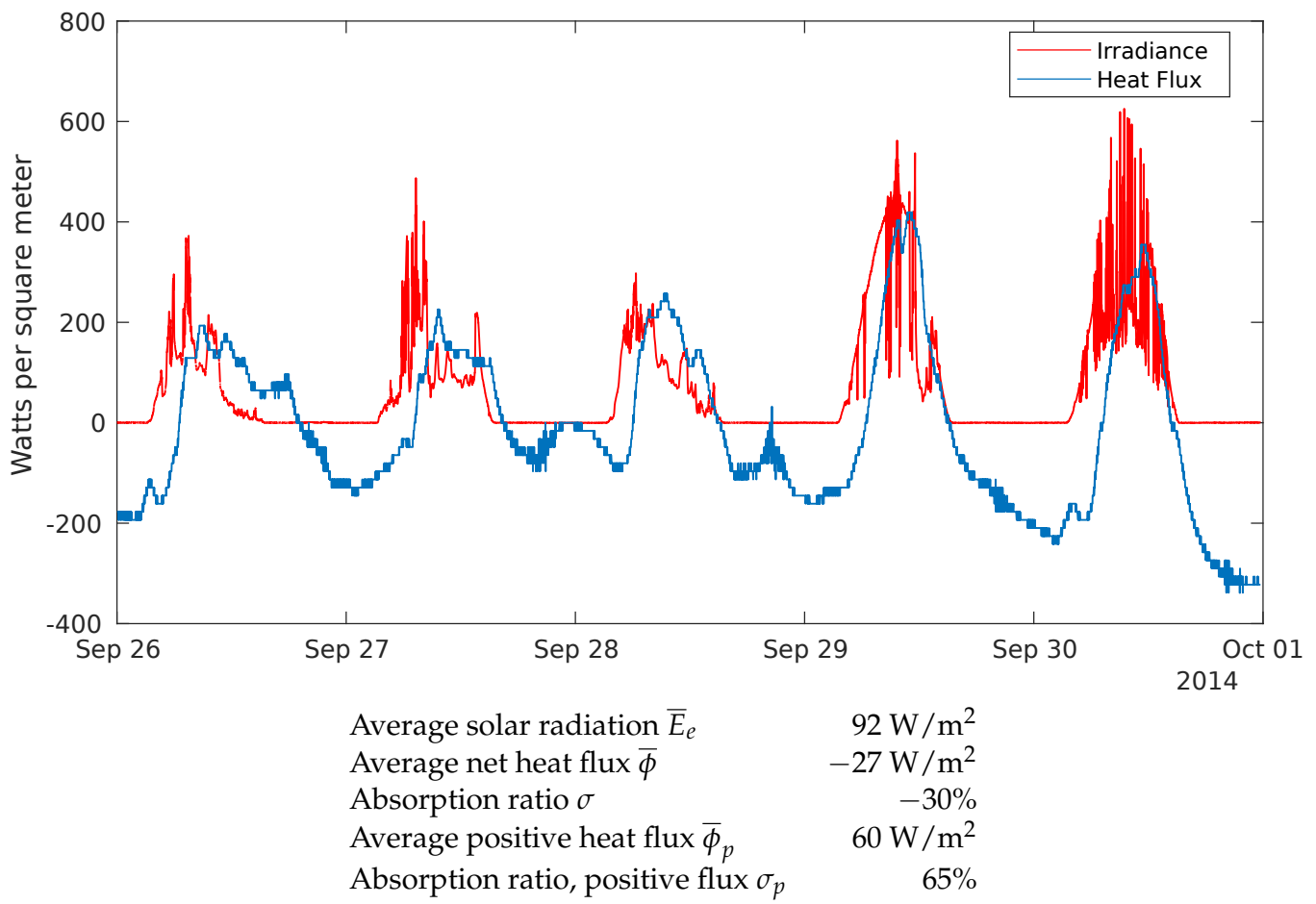

Figure 7. Instantaneous solar irradiation $\bar{E}_{e}\left[\mathrm{~W} / \mathrm{m}^{2}\right]$ and heat flux $\bar{\phi}\left[\mathrm{W} / \mathrm{m}^{2}\right]$ from 26 Sep to 01 Oct 2014 (autumn) as a function of time and estimated average values as a function of time (day).

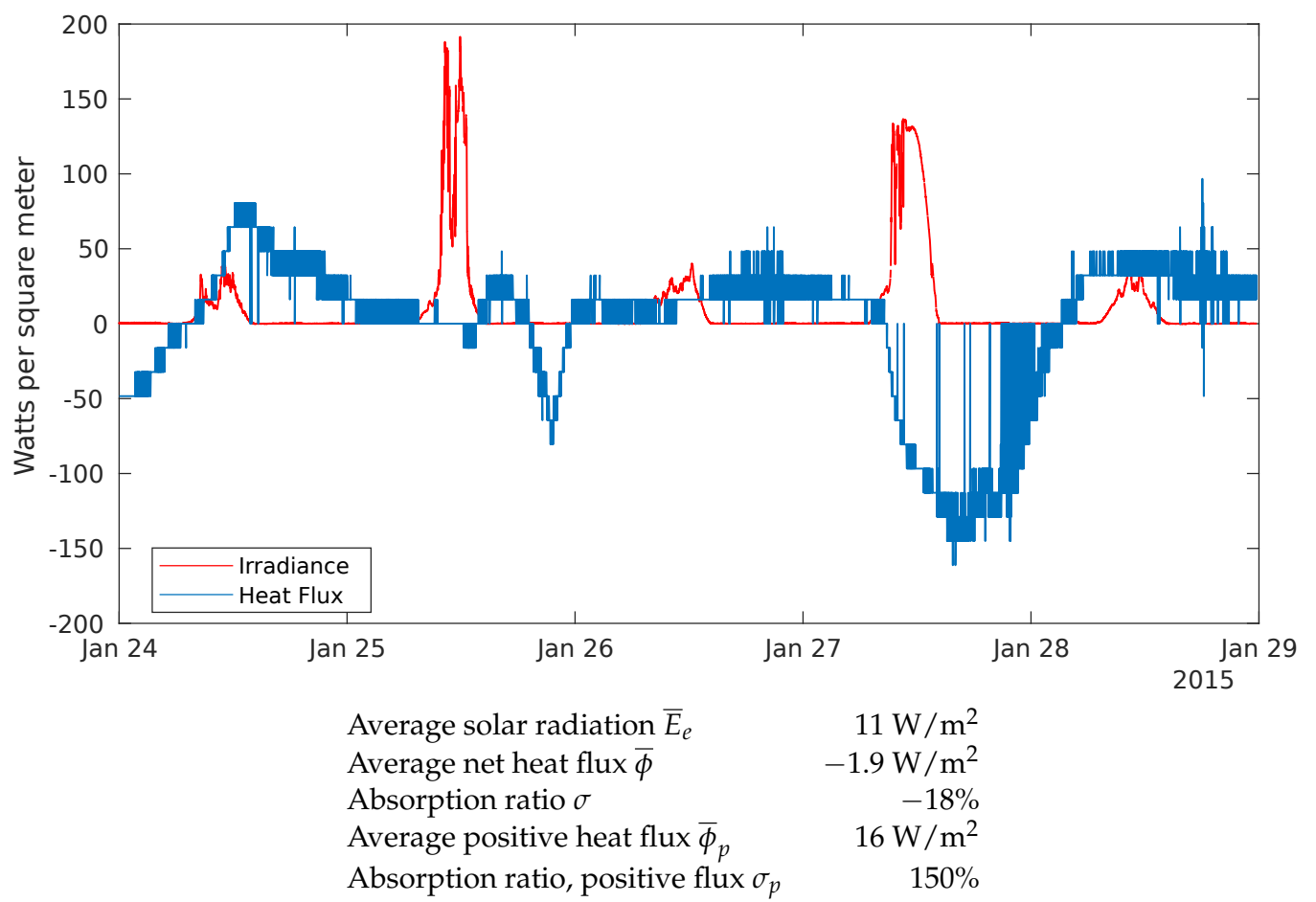

Figure 8. Instantaneous solar irradiation $\left[\mathrm{W} / \mathrm{m}^{2}\right]$ and heat flux $\left[\mathrm{W} / \mathrm{m}^{2}\right]$ from 24 to 29 Jan 2015 (winter), and their estimated average values as a function of time (day). Both irradiance and heat flux are negligible and heat flux is more dependent on the temperature than irradiance. 


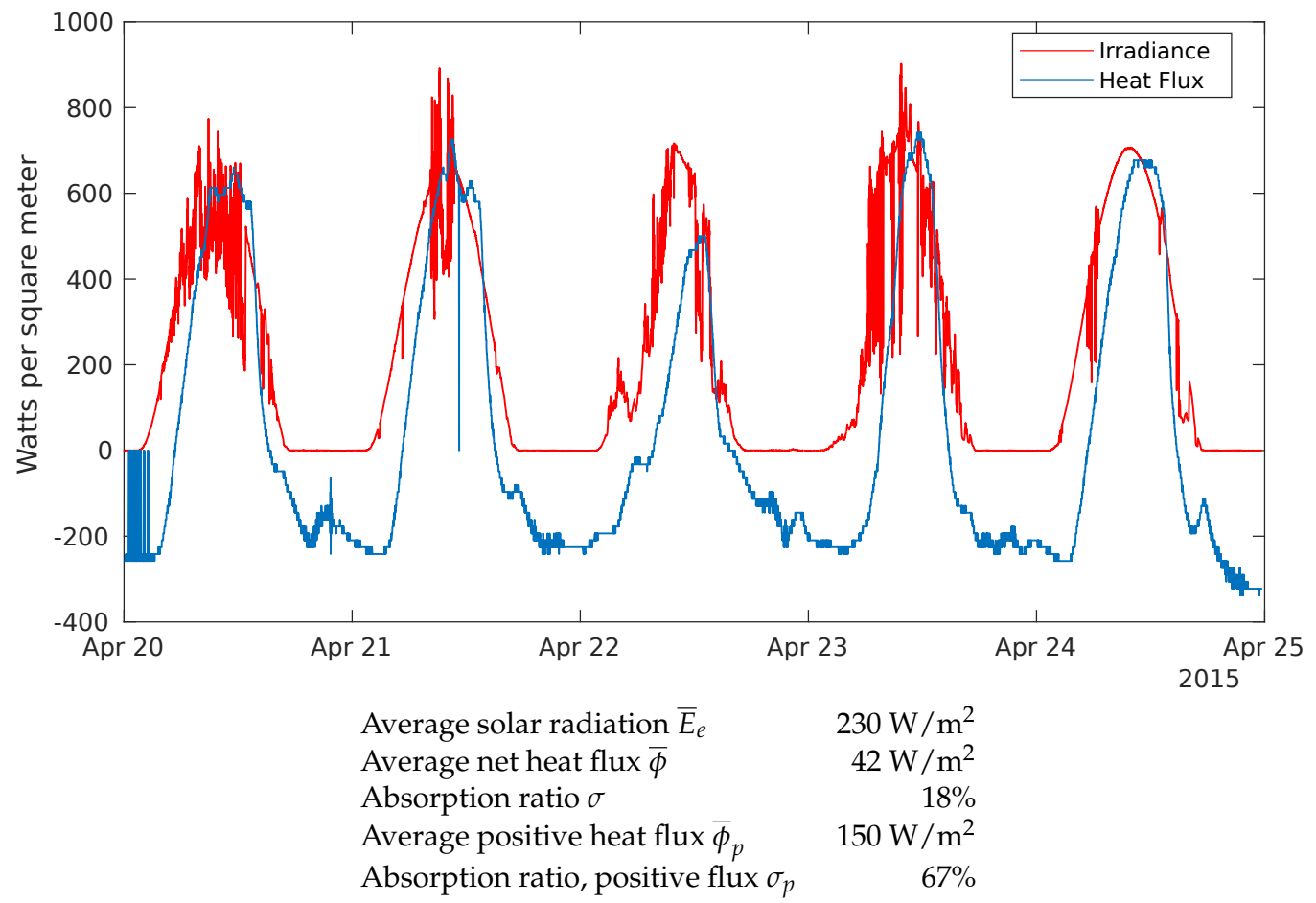

Figure 9. Instantaneous solar irradiation $\bar{E}_{e}\left[\mathrm{~W} / \mathrm{m}^{2}\right]$ and heat flux $\left[\mathrm{W} / \mathrm{m}^{2}\right]$ from 20 to 25 Apr 2015 (spring) as function of time (day) and their estimated average values.

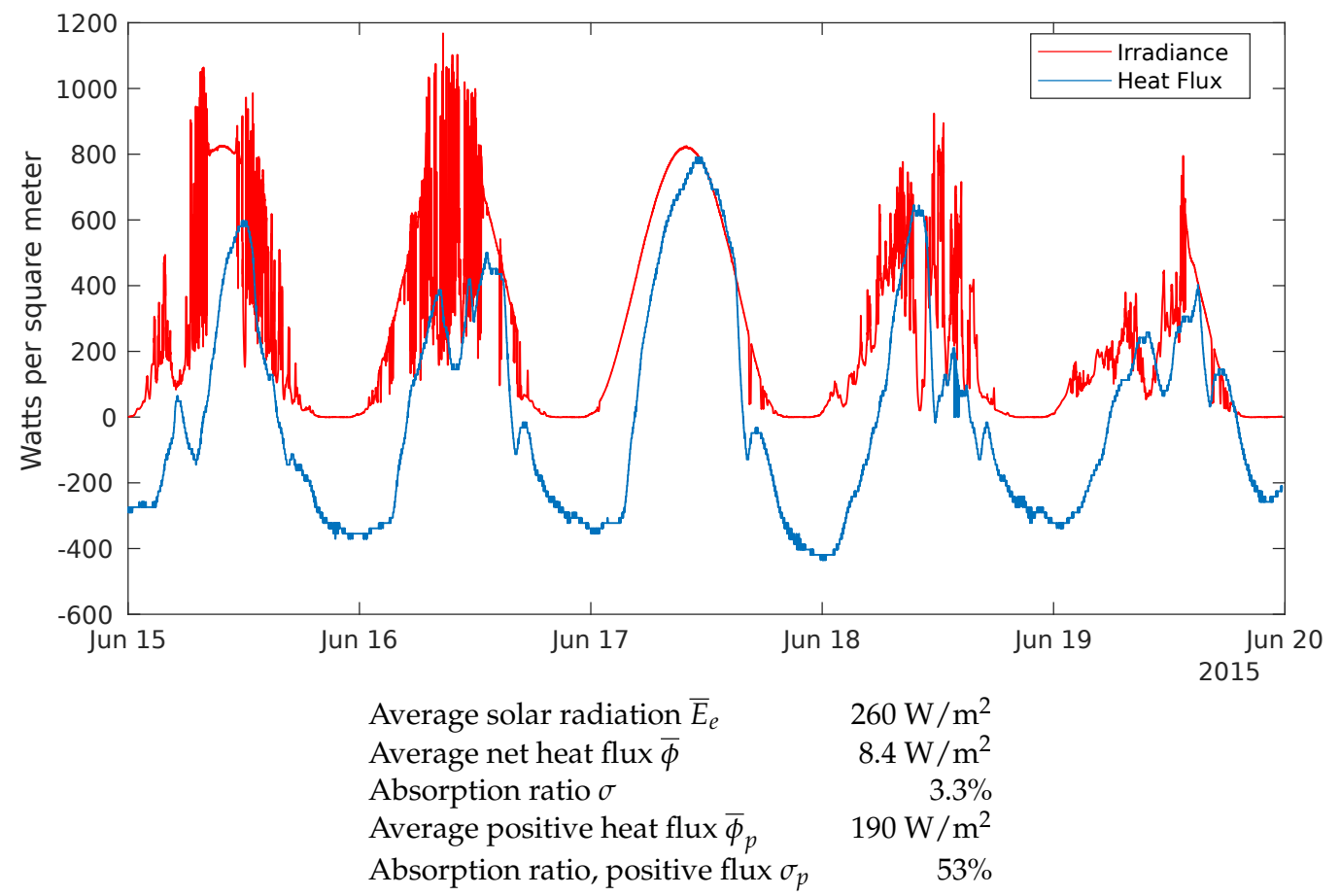

Figure 10. Instantaneous solar irradiation $\bar{E}_{e}\left[\mathrm{~W} / \mathrm{m}^{2}\right]$ and heat flux $\bar{\phi}\left[\mathrm{W} / \mathrm{m}^{2}\right]$ from 15 to 20 Jun 2015 (summer) as a function of time (day) and their estimated average values. 
Because thermal energy loss due to radiation and convection also occurs during daytime, the positive heat flux could be further improved by lowering the temperature of the surface during daytime hours; for example, by collecting and transferring thermal energy to seasonal storage. This would allow the utilization of this urban renewable energy even in cold climate regions. Further research is needed to find the full potential of the asphalt heat collection and storage system.

\subsection{Temperature Distribution Measurements Using DTS}

Using the DTS system, temperatures were measured periodically at certain depths. These measurements helped to analyze how the temperature below the surface is distributed. The selected measurement depths in this research are $0.5 \mathrm{~m}, 1 \mathrm{~m}, 1.5 \mathrm{~m}, 3 \mathrm{~m}, 5 \mathrm{~m}$, and $10 \mathrm{~m}$. Measurements for a period of one year are represented in Figure 11. From April to September, temperatures rise in the shallowest layers. Instead, from October to March the temperatures decrease. At the depth of $10 \mathrm{~m}$ the differences in temperature in the shallowest layers have no effect anymore.

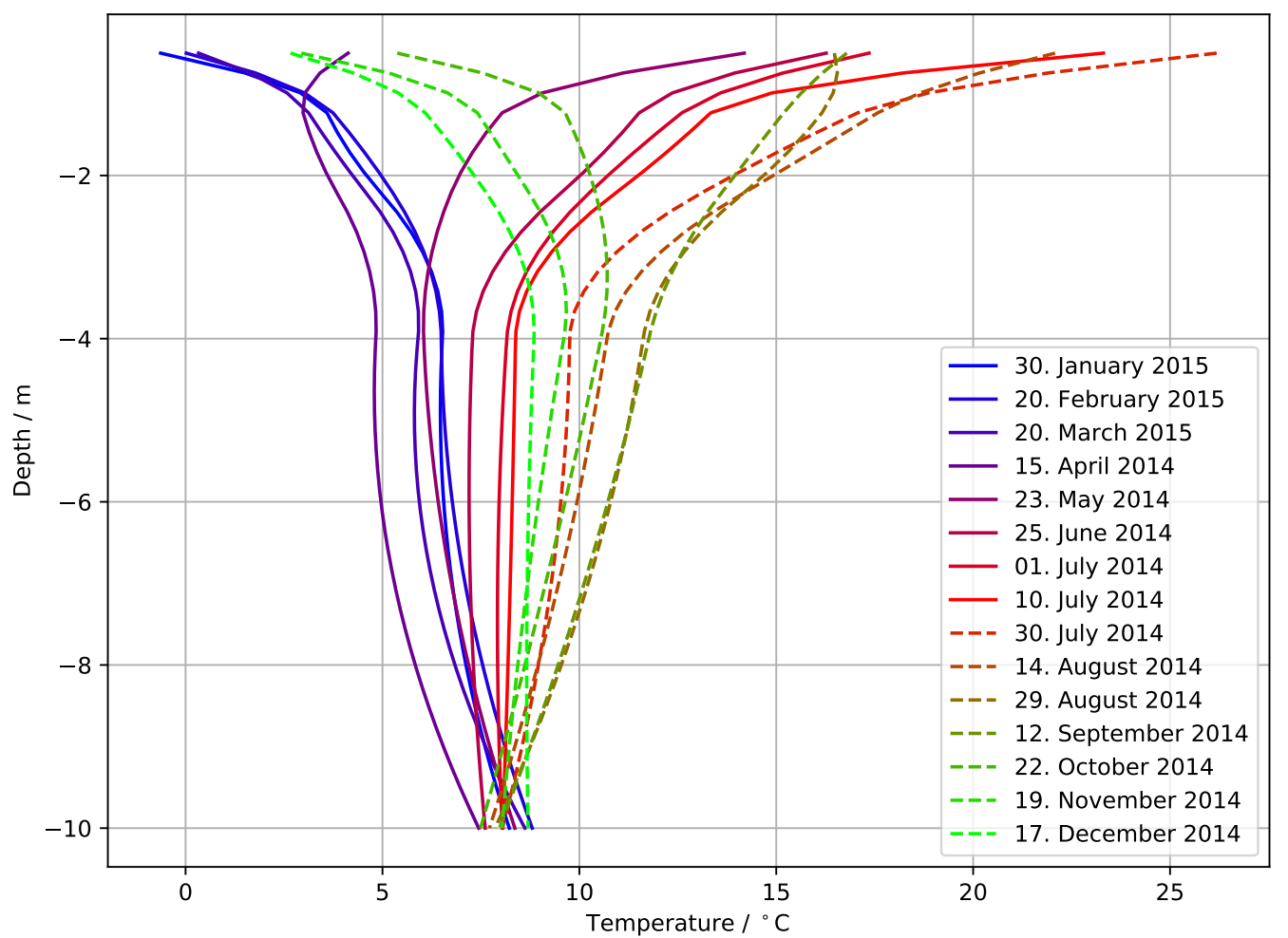

Figure 11. Seasonal soil temperatures at different depths from the surface according to the DTS measurements. During the summer (April-September) temperatures near the surface increase, and during winter months (October-March) the surface is the coldest. At $10 \mathrm{~m}$ depth the effect of the Sun is diminished.

Figure 12 represents the temperature changes of the upper layers of the ground from the surface down to $10 \mathrm{~m}$. The data, acquired from the DTS system, clearly indicates that the deeper layers of the soil react to the heat flux with delay compared to the shallowest layers of the soil. This delay depends on soil type and heat conductivity, $k$. The curves for July and October show that the shallowest layers are already cooled down in October, but the temperatures of depths below $4 \mathrm{~m}$ tend to stay steady. The curves for October and December show that while the shallowest layers keep cooling down, the temperatures of deeper layers also drop. After the snow melts in April, the temperature of the shallowest layer begins to increase but the deeper layers are not affected. During May and the following months of summer, the temperatures continue to increase. Deeper layers are always more 
steady than the surface, and they absorb or release thermal energy much more slowly. The temperature change near the surface is positive between April and August and negative from the beginning of August until the beginning of March. The deeper layers of soil keep the thermal energy longer than the surface layer, and therefore, the cumulative thermal energy begins decreasing in the middle of October. When fast temperature increase occurs on the shallowest layers, some thermal energy can be delivered to the deeper layers to be stored.

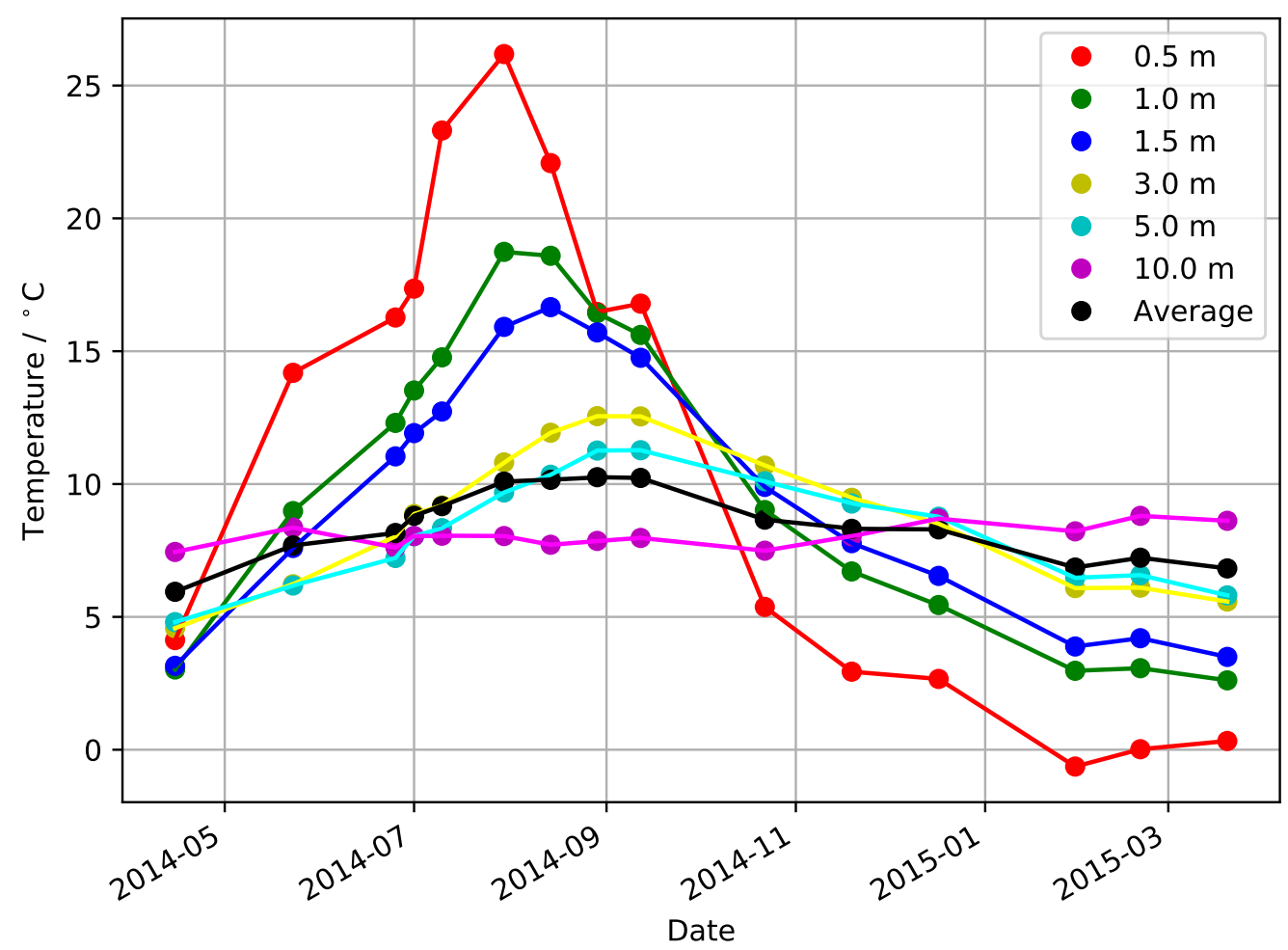

Figure 12. Soil temperatures measured at different depths $(0.5 \mathrm{~m}, 1.0 \mathrm{~m}, \ldots, 10 \mathrm{~m})$ and the weighted average temperature of the whole $10 \mathrm{~m}$ deep layer.

Figure 13 shows the solar irradiation and the cumulative heat flux from asphalt to the deeper soil layers. In addition to showing the net heat flux, the negative and positive parts of the heat flux are also integrated separately to obtain a better understanding of the flow. The cumulative net flow and the temperature of the soil are increasing until the 26th of September, when the cumulative irradiance is $870 \mathrm{kWh} / \mathrm{m}^{2}$; cumulative positive, negative, and net flows are $610 \mathrm{kWh} / \mathrm{m}^{2}, 460 \mathrm{kWh} / \mathrm{m}^{2}$, and $150 \mathrm{kWh} / \mathrm{m}^{2}$, respectively. The positive, negative, and net flows correspond to $70 \%, 53 \%$, and $17 \%$, respectively, of the cumulative solar irradiance.

Figures 12 and 13 are not directly comparable, since they contain measurements taken in different years, but show similar results. Furthermore, the heat flux of the asphalt surface is not directly related to the internal heat exchanges inside the soil. Better conformance is obtained by comparing the cumulative heat flux with the average temperature through all soil layers, shown by the black line in Figure 12. 


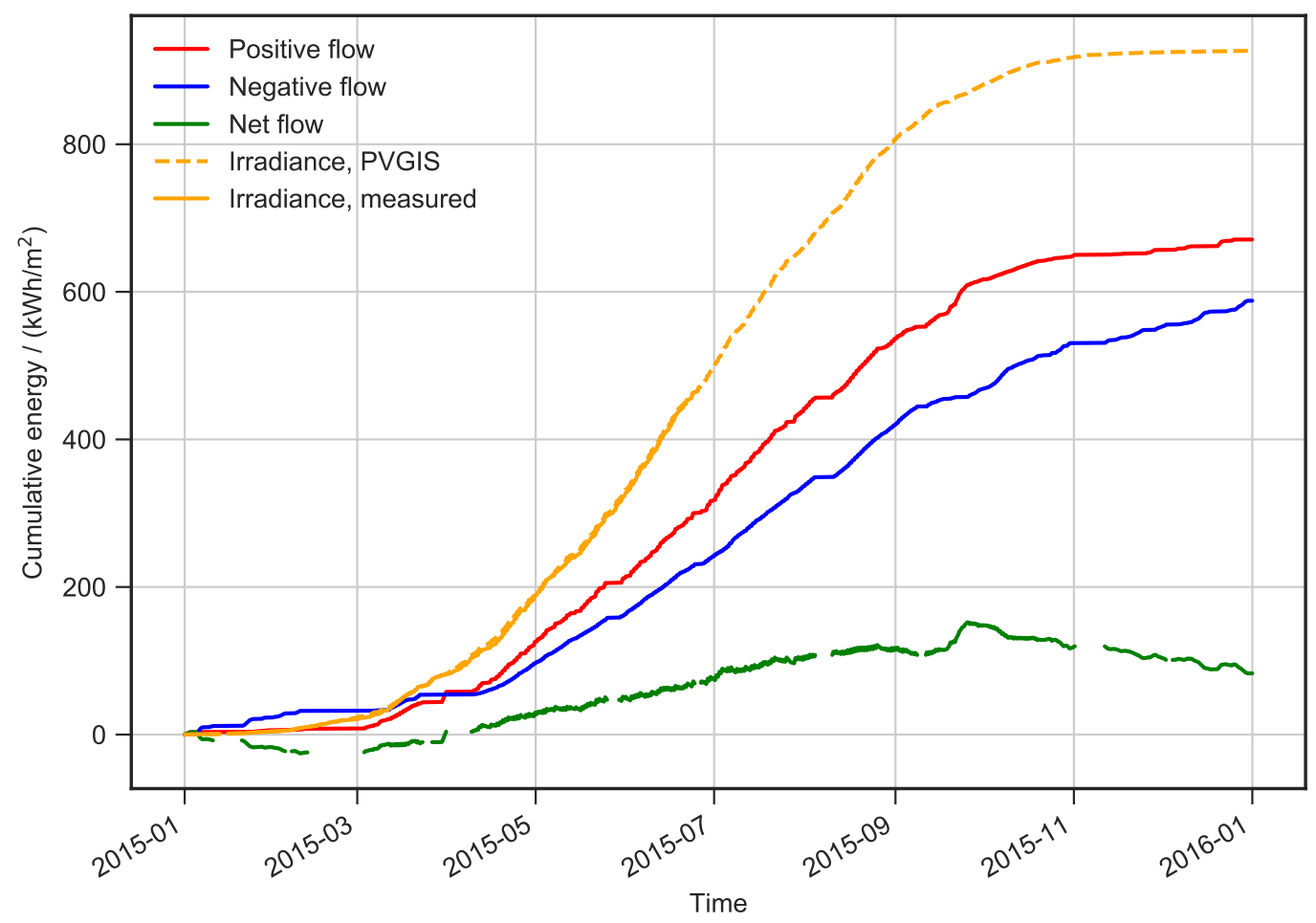

Figure 13. Hourly integrated cumulative irradiance and cumulative heat flux under the asphalt layer over an annual cycle. The net flow consists of the cumulative hourly positive flow into the ground and the cumulative hourly negative flow escaping from the ground. After the warming period, in 26th of September the positive flow is about $70 \%$ of the solar irradiance and the net flow is only about $17 \%$ of it. Irradiance PVGIS is the Solar irradiance estimated using the Photo Voltaic Geographical Information System $[36,37]$.

\section{Discussion and Conclusions}

The data collected in this research make it possible to analyze the performance of the asphalt as a heat collection system during any time of the year. Selected periods of five-day data from every season of the year were analyzed and are represented in Figures 7-10.

When thermal energy is collected by the asphalt layer, the temperature rises, causing a temperature gradient that drives a heat flux through the soil, according to Fourier's law, $\phi=-k \nabla T$. Here $k$ is the thermal conductivity $[k]=\mathrm{W} / \mathrm{m} \mathrm{K}$, and $T$ is the temperature $[T]=\mathrm{K}$. The temperature distributions shown in Figure 11 reveal a high gradient in the topmost gravel layer and a gentler sloping gradient in the deeper layers, such as clay and bedrock. The same observation was seen in the preceding laboratory measurements as well, as reported in [14]. This structure is not desirable for solar energy storage. The thermal energy flowing through the asphalt is not efficiently distributed in the bigger soil volume because it is dissipated back to the atmosphere during the night until the thermal energy penetrates deeper layers (Figure 13). The heat loss can be eliminated by decreasing the soil surface temperature close to the ambient temperature by transferring the thermal energy from the surface. For this purpose, the model in which the energy is harvested from the surface and stored $6 \mathrm{~m}$ under the surface, expressed by Ho et al. [15], could be a working solution. The ground structure could be optimized by increasing the conductivity of the surface by changing the materials or by irrigation. According to Loomans et al. [6] the thermal energy could be harvested inside the asphalt, between two asphalt layers. In their model there are several layers-a thin asphalt layer on the surface, the asphalt pavement layer, and an asphalt layer with heat transfer tubes, and beneath them, asphalt layers again.

Figures 12 and 13 indicate that the net heat flux becomes positive during March or April, depending on the year, and turns back to negative in September or October. The surface reaches its peak temperature at the end of July but remains warm enough to continue driving positive net 
heat flux to the ground until the 26th of September. The average net heat flux is less than $15 \%$ of the available irradiance due to the nighttime thermal energy losses, while the average positive thermal energy is $64 \%$ of the irradiance. This positive heat flux could be more efficiently utilized by reducing nighttime losses, which were, according to Table 3,3/4 of the positive heat flux during spring and summer, and even higher during autumn.

Table 3. Average solar irradiance, heat flux, and absorption ratios over five day periods in all seasons. The first three rows represent the average net heat collection values over the whole period and the next two rows represent the corresponding values for positive values.

\begin{tabular}{lrrrrr}
\hline Parameter & Autumn & Winter & Spring & Summer & Yearly Average \\
\hline Average solar irradiance $\bar{E}_{e}$ & $92 \mathrm{~W} / \mathrm{m}^{2}$ & $11 \mathrm{~W} / \mathrm{m}^{2}$ & $230 \mathrm{~W} / \mathrm{m}^{2}$ & $260 \mathrm{~W} / \mathrm{m}^{2}$ & $148 \mathrm{~W} / \mathrm{m}^{2}$ \\
Average net heat flux $\bar{\phi}$ & $-28 \mathrm{~W} / \mathrm{m}^{2}$ & $-1.9 \mathrm{~W} / \mathrm{m}^{2}$ & $42 \mathrm{~W} / \mathrm{m}^{2}$ & $8.4 \mathrm{~W} / \mathrm{m}^{2}$ & $9.5 \mathrm{~W} / \mathrm{m}^{2}$ \\
Absorption ratio $\sigma$ & $-30 \%$ & $-18 \%$ & $18 \%$ & $3.3 \%$ & $6.4 \%$ \\
\hline Average positive heat flux $\bar{\phi}_{p}$ & $60 \mathrm{~W} / \mathrm{m}^{2}$ & $16 \mathrm{~W} / \mathrm{m}^{2}$ & $150 \mathrm{~W} / \mathrm{m}^{2}$ & $190 \mathrm{~W} / \mathrm{m}^{2}$ & $104 \mathrm{~W} / \mathrm{m}^{2}$ \\
Absorption ratio, positive flux $\sigma_{p}$ & $65 \%$ & $145 \%$ & $65 \%$ & $73 \%$ & $70 \%$ \\
\hline
\end{tabular}

The measurements revealed that the current efficiency of the asphalt pavement in absorbing solar irradiation during the soil warming period between 1st of January and 26th of September is about $17 \%$ (see Figure 13). If the nighttime escape of thermal energy can be eliminated, transferring thermal energy away from the surface, the efficiency could be up to $70 \%$ in the same time period (Table 3). The efficiency could also be increased by covering the asphalt field with insulating cover during the night. The cumulative irradiance, net heat flux, and positive heat flux in the asphalt field during the soil warming period were $870 \mathrm{kWh} / \mathrm{m}^{2}, 150 \mathrm{kWh} / \mathrm{m}^{2}$, and $610 \mathrm{kWh} / \mathrm{m}^{2}$, respectively. Cumulative irradiance, net heat flux, and positive heat flux during the whole year were $930 \mathrm{kWh} / \mathrm{m}^{2}$, $83 \mathrm{kWh} / \mathrm{m}^{2}$, and $670 \mathrm{kWh} / \mathrm{m}^{2}$, respectively. These results imply that the asphalt layer could potentially collect up to $670 \mathrm{kWh} / \mathrm{m}^{2}$ (see Figure 13), provided that the losses can be properly handled. The temperature of the surface layer is relatively low, exceeding $+20{ }^{\circ} \mathrm{C}$ at $0.5 \mathrm{~m}$ depth only in the middle of the summer. The temperature of the heat collection liquid usually needs to be elevated using heat pumps before it can be used for heating purposes. In some applications, such as melting the snow on the asphalt field or making electricity by using thermocouples [38], it could be used without heat pumps. DTS measurements show (Figure 11) that the annual changes in the soil temperature, caused by the solar radiation, mostly occur within the first $10 \mathrm{~m}$ below the ground level. Identical results have been found by Ho et al. [15].

Some unexpected environmental factors occurred while taking the measurements, such as shadows of cars parking over the measurement area. The long time, which were needed to take the measurements, caused some interruption in data acquisition. These interruptions were mainly caused by battery depletion, software resets due to power shortages, and other unknown reasons. Measurement equipment could be developed by getting an instrument amplifier and backup power. In the future, these losses could be estimated and compensated for using Kalman filters and other estimation methods. In such a study, the asphalt and the layers below it are typically used in Finland. These results must not be generalized if the layers and the surroundings differ from those in this research. The data were acquired during a 1-2 year period, which is relatively short term taking into account the annual variation in weather.

In this research, the heat collecting properties of the existing asphalt fields were analyzed and some suggestions for improving the collection efficiency were made. Three independent methods were used to measure the solar irradiance, heat flux, and soil temperature, to explain the behavior of the asphalt pavement for collecting solar energy. This combination of methods was found to give valuable information for harvesting and storing of solar energy in cold climate region. Further research using thermal simulations and experiments is needed to study how much the active and passive heat transfer mechanisms, such as under-asphalt soil structures, could improve the net thermal energy collection 
efficiency in a practical case. Complementary information could be measured by using a radio net meter to measure the absorption and emission of the asphalt. [6] When the vertical temperature distribution (thermal gradient) in the soil is known, it can be used to optimize geothermal energy harvesting and storing applications in the future. An interesting model with which to apply the results of this study for a snow-melting system was proposed by Ho et al. [15]. The model consists of two pipe lines. The first one is embedded below the pavement and an another is located $6 \mathrm{~m}$ under the surface. The upper pipeline can be used to harvest heat in summer and for snow-melting in winter. Another pipeline can be used as a seasonal energy storage in summer and used for snow-melting in winter. The optimized asphalt pavements could act as solar collectors [1,39] and mitigate the urban heat island (UHI) effect [40].

Author Contributions: Software development, data curation, formal analysis C.C..; validation, C.Ç. and P.V.; methodology, investigation, writing-original draft preparation, visualization, C.Ç. and A.M.; resources, E.H.; writing-review and editing, A.M. and E.H.; supervision, P.V., E.H. and M.E. All authors have read and agreed to the published version of the manuscript.

Funding: This research received no external funding.

Acknowledgments: The authors gratefully acknowledge the financial support of the City of Vaasa and the Graduate School of the University of Vaasa.

Conflicts of Interest: The authors declare no conflict of interest.

\section{References}

1. Bobes-Jesus, V.; Pascual-Muñoz, P.; Castro-Fresno, D.; Rodriguez-Hernandez, J. Asphalt solar collectors: A literature review. Appl. Energy 2013, 102, 962-970. [CrossRef]

2. Bijsterveld, W.T.V.; Houben, L.J.M.; Scarpas, A.; Molenaar, A.A.A. Using Pavement as Solar Collector: Effect on Pavement Temperature and Structural Response:. Transp. Res. Rec. 2001. [CrossRef]

3. Li, C.; Shang, J.; Cao, Y. Discussion on energy-saving taking urban heat island effect into account. In Proceedings of the 2010 International Conference on Power System Technology, Hangzhou, China, 24-28 October 2010; pp. 1-3. [CrossRef]

4. Mäkiranta, A.; Hiltunen, E. Utilizing Asphalt Heat Energy in Finnish Climate Conditions. Energies 2019, 12, 2101. [CrossRef]

5. Majorowicz, J.; Grasby, S.E.; Skinner, W.R. Estimation of Shallow Geothermal Energy Resource in Canada: Heat Gain and Heat Sink. Nat. Resour. Res. 2009, 18, 95-108. [CrossRef]

6. Loomans, M.; Oversloot, H.; De Bondt, A.; Jansen, R.; Van Rij, H. Design tool for the thermal energy potential of asphalt pavements. In Proceedings of the Eighth International IBPSA Conference, Eindhoven, The Netherlands, 11-14 August 2003; pp. 745-752.

7. Hailu, G.; Hayes, P.; Masteller, M. Long-Term Monitoring of Sensible Thermal Storage in an Extremely Cold Region. Energies 2019, 12, 1821. [CrossRef]

8. Mehrpooya, M.; Hemmatabady, H.; Ahmadi, M.H. Optimization of performance of Combined Solar Collector-Geothermal Heat Pump Systems to supply thermal load needed for heating greenhouses. Energy Convers. Manag. 2015, 97, 382-392. [CrossRef]

9. Hesaraki, A.; Holmberg, S.; Haghighat, F. Seasonal thermal energy storage with heat pumps and low temperatures in building projects-A comparative review. Renew. Sustain. Energy Rev. 2015, 43, 1199-1213. [CrossRef]

10. Sibbitt, B.; McClenahan, D.; Djebbar, R.; Thornton, J.; Wong, B.; Carriere, J.; Kokko, J. The Performance of a High Solar Fraction Seasonal Storage District Heating System-Five Years of Operation. Energy Procedia 2012, 30, 856-865. [CrossRef]

11. Lund, J.W.; Freeston, D.H.; Boyd, T.L. Direct utilization of geothermal energy 2010 worldwide review. Geothermics 2011, 40, 159-180. [CrossRef]

12. Mesquita, L.; McClenahan, D.; Thornton, J.; Carriere, J.; Wong, B. Drake Landing Solar Community: 10 Years of Operation. In Proceedings of SWC2017/SHC2017; International Solar Energy Society: Abu Dhabi, UAE, 2017; pp. 1-12. [CrossRef] 
13. Haq, H.M.K.U.; Hiltunen, E. An inquiry of ground heat storage: Analysis of experimental measurements and optimization of system's performance. Appl. Therm. Eng. 2019, 148, 10-21. [CrossRef]

14. Martinkauppi, J.B.; Mäkiranta, A.; Kiijärvi, J.; Hiltunen, E. Thermal Behavior of an Asphalt Pavement in the Laboratory and in the Parking Lot. Sci. World J. 2015, 2015. [CrossRef]

15. Ho, I.H.; Dickson, M. Numerical modeling of heat production using geothermal energy for a snow-melting system. Geomech. Energy Environ. 2017, 10, 42-51. [CrossRef]

16. File: Fennoscandia.png-Wikimedia Commons, the Free Media Repository. 2019. Available Online: https: / / commons.wikimedia.org/w /index.php?title=File:Fennoscandia.png\&oldid=365664646 ( accessed on 14 January 2020).

17. Finnish Meteorological Institute FMI: Heating Degree Days. Available online: https:/ / en.ilmatieteenlaitos. fi/heating-degree-days (accessed on 13 January 2020).

18. Finnish Meteorological Institute FMI: Monthly Average Air Temperature Data 2014-2016, Klemettilä, Vaasa. Available online: https:/ /ilmatieteenlaitos.fi/havaintojen-lataus\#! (accessed on 28 January 2019).

19. Hall, M.R.; Dehdezi, P.K.; Dawson, A.R.; Grenfell, J.; Isola, R. Influence of the Thermophysical Properties of Pavement Materials on the Evolution of Temperature Depth Profiles in Different Climatic Regions. J. Mater. Civ. Eng. 2012, 24, 32-47. [CrossRef]

20. Strzelczyk, P.; Szewczyk, M.; Gałek, R.; Gil, P. Measurement of solar radiation properties and thermal energy of the atmosphere in Rzeszow. In Zeszyty Naukowe Politechniki Rzeszowskiej. Mechanika; z. 90 [298], nr 4; Rzeszow University of Technology: Rzeszow, Poland, 2018.

21. Van den Box, K. Hukseflux User Manual LP02, Second Class Pyranometer. 2015. Available online: https:/ / www.hukseflux.com/uploads/product-documents/LP02_manual_v1606.pdf (accessed on 12 September 2019).

22. Hoeksema, E. User Manual, HFP01 \& HFP03, Heat Flux Plate/Heat Flux Sensor. 2015. Available Online: https:/ / www.hukseflux.com/uploads/product-documents/HFP01_HFP03_manual_v1721.pdf (accessed on 12 September 2019).

23. Zhu, K.; Blum, P.; Ferguson, G.; Balke, K.D.; Bayer, P. The geothermal potential of urban heat islands. Environ. Res. Lett. 2010, 5, 044002. [CrossRef]

24. Fisher, A.T.; Mankoff, K.D.; Tulaczyk, S.M.; Tyler, S.W.; Foley, N.; WISSARD Science Team. High geothermal heat flux measured below the West Antarctic Ice Sheet. Sci. Adv. 2015, 1, e1500093. [CrossRef]

25. Ouyang, L.B.; Belanger, D. Flow Profiling via Distributed Temperature Sensor (DTS) System-Expectation and Reality. In Proceedings of the Society of Petroleum Engineers, SPE Annual Technical Conference and Exhibition, Houston, TX, USA, 26-29 September 2004. [CrossRef]

26. Coleman, T.I.; Parker, B.L.; Maldaner, C.H.; Mondanos, M.J. Groundwater flow characterization in a fractured bedrock aquifer using active DTS tests in sealed boreholes. J. Hydrol. 2015, 528, 449-462. [CrossRef]

27. Henninges, J.; Zimmermann, G.; Büttner, G.; Schrötter, J.; Erbas, K.; Huenges, E. Fibre-optic temperature measurements in boreholes. In Proceedings of the 7th FKPE-Workshop “Bohrlochgeophysik and Gesteinsphysik", GeoZentrum Hannover, Hannover, Germany, 23-24 October 2003; pp. 23-24.

28. Oryx DTS User Manual v4; Sensornet Ltd.:, London, UK, 2007.

29. Ukil, A.; Braendle, H.; Krippner, P. Distributed Temperature Sensing: Review of Technology and Applications. IEEE Sens. J. 2012, 12, 885-892. [CrossRef]

30. Sayde, C.; Gregory, C.; Gil-Rodriguez, M.; Tufillaro, N.; Tyler, S.; Giesen, N.V.d.; English, M.; Cuenca, R.; Selker, J.S. Feasibility of soil moisture monitoring with heated fiber optics. Water Resour. Res. 2010, 46. [CrossRef]

31. Xu, Q.; Solaimanian, M. Modeling temperature distribution and thermal property of asphalt concrete for laboratory testing applications. Constr. Build. Mater. 2010, 24, 487-497. [CrossRef]

32. Valtanen, E. The Handbook of Math and Physics, Matematiikan ja Fysiikan Käsikirja, 2 ed.; Genesis-kirjat Oy: Jyväskylä, Finland, 2007.

33. Engineering Toolbox. Densities and Heat Capacities of Materials. Available Online: https://www. engineeringtoolbox.com (accessed on 15 December 2019).

34. Blocon, A. EED Earth Energy Designer-Vertical Borehole Design Program for. 2015. Available online: https:/ / www.buildingphysics.com/manuals/EED3.pdf (accessed on 20 October 2019).

35. Ronkainen, N. Properties of Finnish Soil Types; Finnish Environment Institute: Helsinki, Finland, 2012. Available online: https:/ / core.ac.uk/download/pdf/14927376.pdf (Accessed on 5 December 2019). 
36. Gracia, A.M.; Huld, T.; European Commission; Joint Research Centre; Institute for Energy and Transport. Performance Comparison of Different Models for the Estimation of Global Irradiance on Inclined Surfaces: Validation of the Model Implemented in PVGIS; Publications Office: Luxembourg, 2013.

37. European Comission, J.R.G. Photovoltaic Geographical Information System. 2014. Available Online: http:/ / re.jrc.ec.europa.eu/pvgis (accessed on 21 September 2019).

38. Datta, U.; Dessouky, S.; Papagiannakis, A.T. Thermal Energy Harvesting from Asphalt Roadway Pavement. In Advancement in the Design and Performance of Sustainable Asphalt Pavements; Mohammad, L., Ed.; Sustainable Civil Infrastructures; Springer International Publishing: Cham, Switzerland, 2018; pp. 272-286. Available online: https:/ /link.springer.com/chapter/10.1007/978-3-319-61908-8_20 (accessed on 20 February 2020)

39. Basheer Sheeba, J.; Krishnan Rohini, A. Structural and Thermal Analysis of Asphalt Solar Collector Using Finite Element Method. J. Energy 2014, 2014, 602087. [CrossRef]

40. Pascual-Muñoz, P.; Castro-Fresno, D.; Serrano-Bravo, P.; Alonso-Estébanez, A. Thermal and hydraulic analysis of multilayered asphalt pavements as active solar collectors. Appl. Energy 2013, 111, 324-332. [CrossRef]

(C) 2020 by the authors. Licensee MDPI, Basel, Switzerland. This article is an open access article distributed under the terms and conditions of the Creative Commons Attribution (CC BY) license (http:/ / creativecommons.org/licenses/by/4.0/). 